\title{
BUDAYA ORGANSASI DAN KOMPENSASI BERPENGARUH TERHADAP KEPUASAN KERJA GURU
}

\author{
Dede Suryani
}

\author{
Manahan P. Tampubolon \\ manahan_tb@yahoo.com \\ Mesta Limbong \\ Mesta.limbong@uki.ac.id
}

\begin{abstract}
Abstrak
Penelitian ini adalah penelitian kuantitatif. Penelitian kualitatif adalah penelitian berupa angka-angka dan analisis menggunakan statistik. Penelitian ini dilakukan di SD, SMP Pembangunan Jaya Bintaro pada tahun 2019.

Pengambilan sampel dalam penelitian ini mengguakan probability sample yaitu Teknik pengambilan sampel yang memberikan peluang yang sama bagi setiap unsur (anggota) populasi yang dipilih jadi anggota sampel. Dari hasil uji coba intrumen terhadap 20 sampel menunjukan hasil uji validitas setiap variabel terdapat 8 instrumen drop pada variabel Kepuasan Kerja Guru, 5 variabel drop pada Budaya Organisasi dan 15 instrumen drop pada variabel Kompensasi. Kemudian dilakukan penelitian pada 65 responden.

Hasil penelitian untuk uji normalitas Budaya Organisasi terhadap Kepuasan Kerja Guru sebesar 0,200 > 0,05 dan Variabel Kompensasi terhadap Kepuasan Kerja sebesar 0,040 > 0,05. Maka penelitian berdistribusi normal. Nilai signifikansi variabel Budaya Organisasi terhadap Kepuasan Kerja sebesar 0,422 > 0,05 dan Variabel Kompensasi terhadap Kepuasan Kerja sebesar 0,622 >0,05.

Nilai homogenitas antara variabel Budaya Organisai dan Kompensasi terhadap Kepuasan Kerja Guru (Y) sebesar 0,875>0,05. Sehingga dapat disimpulkan bahwa data dalam penelitian ini homogen. Pembuktian yang lainnya nilai F hitung sebesar 5,143 lebih besar dari $\mathrm{F}$ tabel yaitu 3,14 .

Hasil Penelitian menjunjukan adanya pengaruh Budaya Organisasi terhadap Kepuasan Kerja Guru SD, SMP Pembangunan Jaya sebesar dengan 0,587. Pengaruh Kompensasi terhadap Kepuasan Kerja Guru SD, SMP Pembangunan Jaya sebesar 0,598. Dan Budaya Organisasi dan Kompensasi secara Bersama-sama memengaruhi Kepuasan Kerja Guru dengan korelasi kuat sebesar 0,776.
\end{abstract}

Kata kunci: Budaya, Organisasi, Budaya Organisasi, Kompensasi, Kepuasan Kerja 


\begin{abstract}
This research is quantitative research. Qualitative research is a research of figures and analyses using statistics.This research was conducted in Elementary and Junior High School Pembangunan Jaya, Bintaro in 2019.

Sampling in this study probability samples are sampling techniques that provide equal opportunities for each member of the selected population to sample members. From the test results of the instrument against 20 samples showing the validity test result of each variable there are 8 drop instruments on the teacher work satisfaction variable, 5 drop variables on the organizational culture and 15 drop instruments on the compensation variable. Research was then conducted on 65 respondents.

The results of the research to test the normality of the organizational culture of the teachers ' work satisfaction of $0.200>0.05$ and the compensation variable to job satisfaction of $0.040>0.05$. Then the research is normal distribution. The significance value of the organizational culture variable to work satisfaction amounted to $0.422>$ 0.05 and the compensation variable to job satisfaction of $0.622>0.05$.

The value of homogeneity between the organizational culture variable and the compensation to the teacher's work satisfaction $(Y)$ amounted to 0.875 > 0.05. So it can be concluded that the data in this research is homogeneous. The other proof of $F$ value count of 5.143 is greater than the F table of 3.14.

The research results in the presence of the influence of organizational culture on the work satisfaction of Elementary and Junior High School Pembangunan Jaya with 0.587.The effect of compensation on the work satisfaction of elementary school teachers, Pembangunan Jaya 0.598.And organization culture and compensation jointly affects teacher work satisfaction with a strong correlation of 0.776.
\end{abstract}

Keyword: culture, organization, organizational culture, compensation, job satisfaction 


\section{A. PENDAHULUAN}

\section{Latar Belakang}

Dalam mengoptimalkan Kegiatan Belajar Mengajar (KBM) dikelas, guru memiliki fungsi strategis bagi siswa. Proses tersebut bisa berjalan secara optimal jika mendapat dukungan seperti situasi lingkungan kerja yang memberikan support pada setiap guru untuk berprestasi dan memaksimalkan tugasnyaGuru yang merasa puas memiliki kecenderungan untuk bekerja lebih terarah, memiliki daya tahan terhadap beban kerja yang tinggi, memiliki intensitas tinggi dalam menghadapi kesulitan kerja. Peningkatan dan optimalisasi fungsi guru dapat direalisasikan dengan adanya dukungan dan kondisi kerja kondusif.

Budaya memiliki peran penuh dalam pencapaian organisasi. Organisasi yang baik merupakan pengaruh dari budaya yang baik, budaya yang tidak baik dipengaruhi oleh organisasi yang tidak baik..Budaya organisasi merupakan pengendali dan arah dalam membentuk sikap dan perilaku para anggota didalam suatu organisasi secara individu maupun kelompok seseorang tidakakan terlepas dari budaya organisasi dan pada umumnya anggota organisasi akan dipengaruhi oleh beraneka ragamnya sumber daya yang ada. Guru yang merasa puas memiliki kecenderungan untuk bekerja lebih terarah, memiliki daya tahan terhadap beban kerja yang tinggi, memiliki intensitas tinggi dalam menghadapi kesulitan kerja. Peningkatan dan optimalisasi fungsi guru dapat direalisasikan dengan adanya dukungan dan kondisi kerja kondusif. Melihat berbagai masalah yang telah dipaparkan diatas, maka hal ini yang mendorong peneliti untuk mengadakan penelitian tentang budaya organisasi dan kompensasi terhadap pengaruh kepuasan kerja guru SD, SMP Pembangunan Jaya.

\section{Identifikasi Masalah}

Dari penjabaran latar belakang, maka dapat diindentifikasikan beberapa masalah yang perlu dikaji lebih jauh, adalah

1) Bagaiamana pengaruh budaya organisasi terhadap kepuasan kerja guru?

2) Bagaimana pengaruh kompensasi terhadap kepuasan kerja guru?

3) Bagaimana pengaruh program sekolah terhadap kepuasan kerja guru?

\section{Rumusan Masalah}

Penelitian ini merumuskan apakah terdapat nilai hubungan variabelvariabel independen terhadap variabel dependen. Apakah terdapat pengaruh variabel budaya organisasi terhadap kepuasan kerja guru?, apakah terdapat pengaruh variabel kompensasi terhadap kepuasan kerja guru?, apakah terdapat pengaruh variabel budaya organisasi, kompensasi, secara bersama-sama terhadap kepuasan kerja guru.

\section{B. PEMBAHASAN}

\section{Pengertian Kepuasan Kerja Guru}


Robbins and Judge (2011:110) menyatakan bahwa kepuasan kerja adalah sikap positif pegawai terhadap pekerjaannya. Sikap positif dari seorang karyawan jika merasa puas akan lebih agresif dalam bekerja, memberikan prestasi yang baik serta kinerja yang baik pula. Sebaliknya jika seorang karyawan tidak merasa puas. Maka akan memberikan sikap negative.

Menurut Hasibuan (2018:202) mengemukakan bahwa kepuasan kerja adalah sikap emosional yang menyenangkan dan mencintai pekerjaannya. Sikap ini dicerminkan oleh moral kerja, kedisiplinan, dan prestasi kerja. Dalam hal ini seorang pegawai akan memberikan perilaku positif dalam bekerja saat kepuasan kerja sudah didapat.

Menurut Mangkunegara (2017: 117) kepuasan kerja adalah suatu perasaan yang menyokong atau tidak menyokong diri pegawai yang berhubungan dengan pekerjaannya maupun dengan kondisi dirinya. Jika merasa puas seorang pegawai akan menyokong segala pekerjaanya memberikan kontribusi yang sangat tinggi begitu pun sebaliknya.

Jadi kepuasan kerja guru adalah sikap atas perasaaan puas atau tidak puas atas pekerjaanya yaitu dalam mengajar dan kontribusi yang diberikan sebagai loyalitas terhadap organisasi sekolah.

\section{Pengertian budaya organisasi}

Menurut Tampubolon (2015: 222) budaya adalah segala sesuatu yang dilakukan, dipikirkan, dan diciptakan oleh manusia dalam masyarakat serta termasuk pengakumulasian sejarah dari objek-objek atau perbuatan yang dilakukan sepanjang waktu (Perucci \& Hamby, 1977).

Winardi (2015: 56) berpendapat bahwa suatu organisasi dapat kita anggap sebagai sebuah kesatuan yang terdiri dari sejumlah komponen yang berinterelasi, dimana pertimbangan serta koordinasinya merupakan kuncikunci bagi upaya maksimasi kinerja serta mengoptimasi efisiensi secara keseluruhan. Dalam berjalannya sebuah organisasi peran serta setiap anggota organisasi untuk mencapai sasaran diperlukan kerjasama dan kolaborasi antara unsur dan aturan organisasiyang telah dirancang.

Sedarmayanti (2016: 99) berpendapat bahwa budaya organisasi merupakan aspek subjektif dari apa yang terjadi di dalam organisasi. Hal ini mengacu kepada abstraksi, seperti nilai dan norma yang meliputi seluruh atau bagian dari bisnis. Hal ini mungkin tidak didefinisikan, didiskusikan atau bahkan diperhatikan, namun budaya dapat memiliki pengaruh penting pada perilaku seseorang. Budaya organisasi merupakan tingkah laku setiap anggota dalam organisasi. Pentingnya komunikasi setiap anggota dalam mencapai suatu tujuan organisasi diharapkan sebagai budaya yang bisa membuat kerja organisasi menjadi efektif.

Budaya organisasi disekolah adalah sikap dan perilaku guru dimana guru mampu berinovasi dalam kegiatan pembelajaran, tenggang rasa sesama guru, serta memiliki kontribusi dari setiap guru terhadap kegiatan-kegiatan disekolah baik kegiatan akademik maupun non akademik.

\section{Pengertian kompensasi}

Handoko (2014: 155) berpendapat bahwa kompensasi adalah segala sesuatu yang diterima para karyawan sebagai balas jasa untuk kerja 
mereka. Karyawan akan mendapatkan kompensasi setelah karyawan tersebut bekerja. Kompensasi yang diberikan untuk membalas jasa karyawan karena telah bekerja untuk perusahaan. Sebagai salah satu kewajiban perusahaan karena karyawan tersebut telah bekerja.

Menurut Simamora (2006: 442) kompensasi merupakan apa yang diterima oleh para karyawan sebagai ganti kontribusi mereka kepada organisasi. Apapun yang telah dilakukan karyawan terhadap perusahaan dalam bekerja, maka karyawan tersebut akan menerima kompensasi sesuai dengan kontribusinya terhadap perusahaan.

Hasibuan (2018:118) berpendapat bahwa kompensasi adalah semua pendapatan yang berbentuk uang, barang langsung atau tidak langsung yang diterima karyawan sebagai imbalan atas jasa yang diberikan kepada perusahaan. Artinya seorang anggota organisasi atau karyawan berhak mendapatkan imbalan atas jasa yang telah diberikan kepada organisasi atau perusahaan. Imbalan yang didapat bisa dalam berupa uang atau barang langsung atau tidak langsung.

Kompensasi adalah imbalan yang diberikan kepada anggota organisasi atau karyawan atas jasa yang diberikan. Imbalannya berupa upah atau gaji ataupun yang lainnya seperti tunjangan hari tua, tunjangan pendidikan, tunjangan kesehatan, dll.

\section{Metode Penelitian}

Penelitian ini menggunakan metode penelitian kuantitatif. Menurut Sugiyono (2018: 7) penelitian kualitatif adalah penelitian berupa angkaangka dan analisis menggunakan statistik. Seperti yang dikemukaan Sugiyono (2018: 14) tujuan penelitian kuantitatif adalah untuk menunjukan hubungan antar variabel. Tujuan penelitian ini adalah menganalisis hubungan budaya organisasi dan kompensasi terhadap kepuasan kerja guru. Terdapat tiga variabel dalam penelitian ini, yaitu:
a. Variabel Y adalah Kepuasan Kerja Guru
b. Variabel X1 adalah Budaya Organisasi
c. Variabel X2 adalah Kompensasi

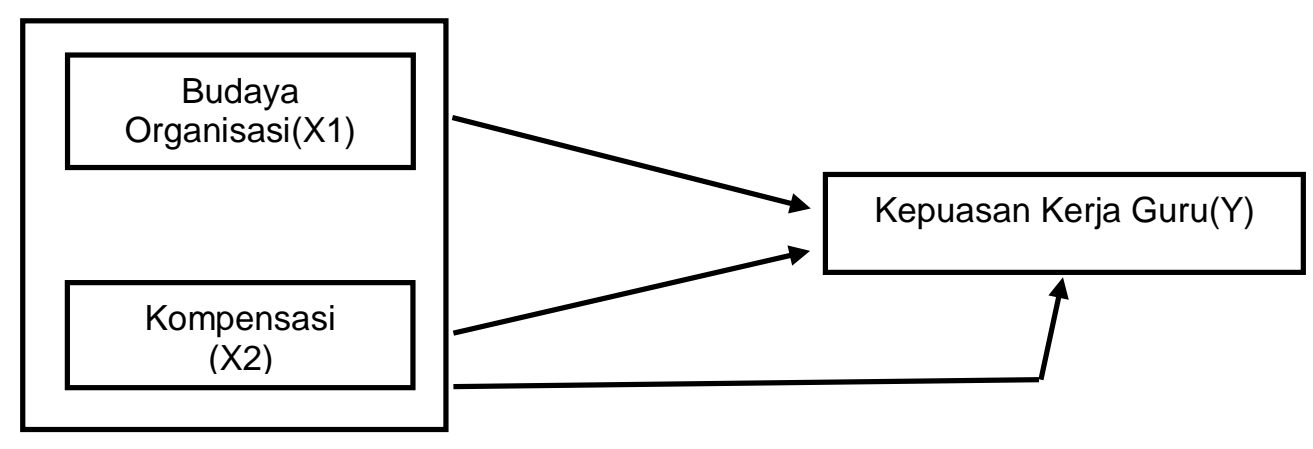

Keterangan:

\section{Gambar 7.1 Rancangan Penelitian}

$\mathrm{X} 1$ = Budaya Organisasi

$\mathrm{X} 2=$ Kompensasi

$\mathrm{Y}=$ Kepuasan Kerja Guru 


\section{a. Populasi}

Sugiyono (2018:215) berpendapat bahwa populasi dapat didefinisikan sebagai wilayah generalisasi yang terdiri dari obyek atau subyek yang mempunyai kuantitas dan karakteristik tertentu yang Populasi dalam penelitian ini adalah guru SD, SMP Pembangunan Jaya baik dalam status guru honor, guru kontrak maupun guru tetap.

\section{Tabel 7.1Jumlah Guru SD, SMP Pembangunan JayaTahun}

Ajaran 2018-2019

\begin{tabular}{|c|l|c|}
\hline No. & Sekolah & Jumlah Guru \\
\hline 1 & SD & 45 \\
\hline 2 & SMP & 20 \\
\hline \multicolumn{2}{|c|}{ Total } & 65 \\
\hline
\end{tabular}

Guru SD Pembangunan Jaya berjumlah 45 orang dengan status honor, kontrak dan tetap. Guru berstatus honor 15 orang, guru berstatus kontrak 5 orang, dan guru berstatus tetap 15 orang. Untuk Guru SMP Pembangunan Jaya berjumlah 20 guru, dengan guru berstatus honor 5 orang, guru kontrak 2 orang dan guru berstatus tetap 12 orang.

b. Teknik sampling

Pengambilan sampel dalam penelitian ini menggunakan probability sampling. Seperti yang dikemukaan Sugiyono (2018: 218) probability sampling adalah teknik pengambilan sampel yang memberikan peluang yang sama bagi setiap unsur (anggota) populasi untuk dipilih menjadi anggota sampel. Teknik yang diambil yaitu Proportionate Stratified Random Sampling dimana jumlah sampel pada masingmasing strata sebanding dengan jumlah anggota populasi pada masingmasing stratum populasi. Banyaknya sampel untuk penelitian ini adalah 65 guru.

1. Teknik Pengumpulan Data

Teknik pengumpulan dalam penelitian ini dengan menggunakan angket skala Likert. Menurut Sukardi (2008: 146) skala likert digunakan oleh para peneliti guna mengukur persepsi atau sikap seseorang. Skala ini menilai sikap atau tingkah laku yang diinginkan oleh para peneliti dengan cara mengajukan beberapa pertanyaan kepada responden. Kemudian responden diminta memberikan pilihan jawaban atau respon terhadap skala ukur yang disediakan.

Tabel 8.1Bobot dan Kategori Pengukuran Data

\begin{tabular}{|c|c|}
\hline Butir Bobot & Kategori \\
\hline SS (Sangat Setuju) & 5 \\
\hline S (Setuju) & 4 \\
\hline RG (Ragu-ragu) & 3 \\
\hline TS (Tidak Setuju) & 2 \\
\hline STS (Sangat Tidak setuju) & 1 \\
\hline
\end{tabular}

2. Kisi-kisi Instrumen

Kisi-kisi instrumen adalah indikator setiap variabel yang dikembangkan dalam pernyataan yang terdapat dalam kuesioner. 
Pernyataan-pernyataan tersebut mewakili setiap indikator variabel. Sehingga diharapkan pernyataan yang diberikan tidak melenceng dari indikator variabel. Berikut adalah kisi-kisi instrumen variabel Kepuasan Kerja Guru, Budaya Organisasi dan Kompensasi.

a. Variabel Kepuasan Kerja Guru

Tabel 9.1 Kisi-kisi Instrumen Kepuasan Kerja Guru

\begin{tabular}{|c|c|c|c|c|}
\hline \multirow[t]{2}{*}{ Variabel } & \multirow[t]{2}{*}{ Indikator } & \multicolumn{2}{|c|}{$\begin{array}{l}\text { Nomor Butir } \\
\text { Pertanyaan }\end{array}$} & \multirow[t]{2}{*}{ Jumlah } \\
\hline & & + & - & \\
\hline \multirow[t]{2}{*}{$\begin{array}{l}\text { Kepuasan } \\
\text { Kerja Guru }\end{array}$} & $\begin{array}{l}\text { Faktor-faktor yang berkaitan } \\
\text { dengan individu }\end{array}$ & $\begin{array}{l}1,2,4,5,6 \\
7,9,10\end{array}$ & 3,8 & 10 \\
\hline & $\begin{array}{l}\text { Faktor-faktor yang berkaitan } \\
\text { dengan organisasi }\end{array}$ & $\begin{array}{l}11,12,14, \\
15,16,17, \\
18,19,20\end{array}$ & 13 & 10 \\
\hline \multicolumn{2}{|r|}{ Jumlah } & 17 & 3 & 20 \\
\hline
\end{tabular}

b. Budaya Organisasi Sekolah

Tabel 9.2 Kisi-kisi Instrumen Budaya Organisasi Sekolah

\begin{tabular}{|c|c|c|c|c|}
\hline \multirow[t]{2}{*}{ Variabel } & \multirow[t]{2}{*}{ Indikator } & \multicolumn{2}{|c|}{$\begin{array}{c}\text { No. Butir } \\
\text { Pertanyaan }\end{array}$} & \multirow[t]{2}{*}{ Jumlah } \\
\hline & & + & - & \\
\hline \multirow[t]{6}{*}{$\begin{array}{l}\text { Budaya } \\
\text { Organisasi }\end{array}$} & $\begin{array}{l}\text { 1. Inovatif } \\
\text { memperhitungkan resiko }\end{array}$ & $1,2,4,5$ & 3 & 5 \\
\hline & $\begin{array}{l}\text { 2. Memberikan perhatian } \\
\text { pada setiap masalah } \\
\text { secara detail }\end{array}$ & $6,7,8,9,10$ & - & 5 \\
\hline & $\begin{array}{l}\text { 3. Berorientasi terhadap } \\
\text { hasil yang akan dicapai }\end{array}$ & $\begin{array}{c}11,12,13 \\
15\end{array}$ & 14 & 5 \\
\hline & $\begin{array}{l}\text { 4. Berorientasi kepada } \\
\text { semua kepentingan } \\
\text { karyawan }\end{array}$ & $\begin{array}{l}16,17,18 \\
19,20\end{array}$ & - & 5 \\
\hline & 5. Agresif dalam bekerja & $21,22,24$ & $\begin{array}{l}23 \\
25\end{array}$ & 5 \\
\hline & $\begin{array}{l}\text { 6. Mempertahankan dan } \\
\text { menjaga stabilitas kerja }\end{array}$ & $\begin{array}{c}25,26,27 \\
28,29\end{array}$ & 30 & 5 \\
\hline & Jumlah & 25 & 5 & 30 \\
\hline
\end{tabular}

c. Kompensasi

Tabel 9.3 Kisi-kisi Instrumen Kompensasi

\begin{tabular}{|c|l|c|c|c|}
\hline \multicolumn{1}{|c|}{ Variabel } & \multicolumn{1}{|c|}{ Indikator } & \multicolumn{2}{c|}{$\begin{array}{c}\text { No. Butir } \\
\text { Pertanyaan }\end{array}$} & \multirow{2}{*}{ Jumlah } \\
\cline { 2 - 4 } \multirow{2}{*}{$\begin{array}{l}\text { Kompensa } \\
\text { si }\end{array}$} & $\begin{array}{l}\text { 1. Gaji atau upah yang } \\
\text { diterima memenuhi } \\
\text { kebutuhan sehari-hari, } \\
\text { sesuai dengan aturan yang } \\
\text { ditetapkan, dapat } \\
\text { meningkatkakan semangat } \\
\text { kerja, meningkatkan } \\
\text { kepuasan kerja }\end{array}$ & $1,2,3,4$, & 5 & 5 \\
\cline { 2 - 5 } & 2. Pemberian insentif \\
terhadap kepuasan kerja & $6,7,8$ & 9,10 & 5 \\
\cline { 2 - 5 } & 3. Pemberian tunjangan & $11,12,13$, & 14 & 5 \\
\hline
\end{tabular}




\begin{tabular}{|c|c|c|c|c|}
\hline & $\begin{array}{l}\text { sesuai dengan aturan yang } \\
\text { ditetapkan, tunjangan } \\
\text { profesi secara rutin, dalam } \\
\text { meningkatkan kepuasan } \\
\text { kerja. }\end{array}$ & 15 & & \\
\hline & $\begin{array}{l}\text { Pemberian wewenang } \\
\text { dalam meningkatkan } \\
\text { kemampuan, pemberian } \\
\text { reward dalam } \\
\text { meningkatkan kepuasan } \\
\text { kerja }\end{array}$ & $\begin{array}{c}16,18,19 \\
20\end{array}$ & 17 & 5 \\
\hline 5 & $\begin{array}{l}\text { Rekan kerja yang } \\
\text { menyenangkan dalam } \\
\text { meningkatkan semangat } \\
\text { kerja, dan memberikan } \\
\text { kenyamanan dalam } \\
\text { bekerja }\end{array}$ & $\begin{array}{c}21,22,23 \\
24\end{array}$ & 25 & 5 \\
\hline & $\begin{array}{l}\text { Pemanfaatan media } \\
\text { pembelajaran memberikan } \\
\text { kemudahan saat mengajar }\end{array}$ & $26,27,28,29$ & 30 & 5 \\
\hline & Jumlah & 23 & 7 & 30 \\
\hline
\end{tabular}

3. Uji coba

Setelah dilakukan uji coba, ternyata pernyataan yang valid untuk variabel Kepuasan Kerja Guru adalah 12 pernyataan dan 8 pernyataan yang tidak valid. Pada variabel Budaya Organisasi terdapat 25 pernyataan valid dan 5 pernyataan tidak valid. Sedangkan untuk variabel Kompensasi terdapat 15 pernyataan valid dan 15 pernyataan tidak valid. Selanjutnya dilakukan uji reliabelitas dengan hasil semua variabel reliabel.

4. Uji validitas

Menurut Sugiyono (2018:193) untuk mengetahui taraf hubungan atau korelasi antara variabel prediktor $(\mathrm{X})$ dan variabel kriterium (Y) maka dihitung dengan koefisien korelasi (r).Dari hasil uji coba instrumen, selanjutnya dilakukan perbaikan instrumen setiap variabel. Dengan memperhatikan pernyataan-pernyataan sehingga pernyataan lebih konsisten dan terarah sesuai dengan apa yang ingin di ukur. Kemudian dilakukan penelitian terhadap 65 responden guru SD, SMP Pembangunan Jaya. Berikut adalah uji validitas penelitian variabel Kepuasan Kerja Guru, Budaya Organisasi dan Kompensasi.

Tabel 11.1 Hasil Penelitiann Uji Validitas Instrumen

\begin{tabular}{|c|c|c|c|c|}
\hline Variabel & $\mathbf{R}$ tabel & $\begin{array}{l}\text { Instrumen } \\
\text { Valid }\end{array}$ & $\begin{array}{l}\text { Instrumen } \\
\text { drop }\end{array}$ & Keterangan \\
\hline $\begin{array}{l}\text { Kepuasan } \\
\text { Kerja }\end{array}$ & 0,422 & 19 & 1 & $\begin{array}{c}\text { Butir pernyataan } \\
\text { nomor } 3\end{array}$ \\
\hline $\begin{array}{l}\text { Budaya } \\
\text { Organisasi }\end{array}$ & 0,422 & 30 & 0 & \\
\hline Kompensasi & 0,422 & 28 & 2 & $\begin{array}{c}\text { Butir pernyataan } 5 \text { dan } \\
10\end{array}$ \\
\hline \multicolumn{2}{|c|}{ Jumlah } & 77 & 3 & \\
\hline
\end{tabular}


5. Uji reliabelitas

Uji reliabilitas dilakukan dengan bantuan program SPSS 25, diuji dengan statistik Alpha Cronbach. Data dikatakan reliabel bila nilai Alpha Cronbach lebih besar dari 0,05.

Tabel 12.1 Hasil Penelitian Uji Reliabelitas

\begin{tabular}{|c|c|c|}
\hline Variabel & Alpha Cronbach & Status \\
\hline Budaya Organisasi & 0,940 & Reliabel \\
\hline Kompensasi & 0,903 & Reliabel \\
\hline Kepuasan Kerja & 0,887 & Reliabel \\
\hline
\end{tabular}

Dari hasil penelitian instrument pada tabel 12.1 untuk uji reliabelitasnya semua variabel reliabel karena nilai Apha Cronbach lebih besar dari 0,05. Sehingga dapat disimpulkan bahwa semua variabel reliabel.

6. Statistik Deskriptif

Statistik deskriptif merupakan bagian dari statistik yang digunakan untuk menyimpulkan dan mempresentasikan serta menggambarkan karakteristrik dari data yang digunakan.

Tabel 13.1 Statistik Deskriptif

\begin{tabular}{|l|c|c|c|}
\hline \multirow{2}{*}{ Statistik } & \multicolumn{3}{|c|}{ Variabel } \\
\cline { 2 - 4 } & $y$ & $x_{1}$ & $x_{2}$ \\
\hline Mean & 3,90 & 4,30 & 4,16 \\
\hline Deviasi standar & 0,76 & 0,58 & 0,69 \\
\hline Minimun & 2,90 & 3,50 & 3,20 \\
\hline Maksimum & 5,00 & 5,00 & 5,00 \\
\hline Range & 3,00 & 2,20 & 2,70 \\
\hline
\end{tabular}

Berdasarkan deskripsi data statistik pada tabel 13.1 dapat dilihat bahwa nilai rata-rata untuk $y$ mendapat skor 3,90 artinya ada responden yang ragu-ragu dengan pernyataan yang terdapat dalam variabel $y$. Jika dibandingkan dengan variabel $x_{1}, x_{2}$ nilai rata-rata menunjukan di atas angka 4 , maka dapat disimpulkan bahwa ratarata variabel mendapatkan nilai tertinggi dari responden. Nilai maksimum semua variabel 5 hal ini berarti bahwa responden sangat setuju dengan semua pernyataan yang terdapat dalam kuesioner. Nilai minimum variabel $y$ adalah 2,90 berarti ada responden yang ragu-ragu atau netral dengan pernyataan yang terdapat dalam variabel $y$. Nilai minimum variabel $x_{1}$ adalah 3,50 berarti ada responden yang ragu-ragu atau netral dengan pernyataan yang terdapat dalam variabel $x_{1}$. Dan nilai minimum variabel $x_{2}$ adalah 3,20 berrati ada responden yang ragu-ragu atau netral dengan pernyataan yang terdapat dalam variabel $x_{2}$.

a. Kepuasan Kerja Guru

Tabel 13.2 Distribusi Frekuensi Kepuasan Kerja

\begin{tabular}{|c|c|c|c|c|}
\hline No & $\begin{array}{c}\text { Interval } \\
\text { Kelas }\end{array}$ & $\begin{array}{c}\text { Frekuensi } \\
\text { Absolut }\end{array}$ & $\begin{array}{c}\text { Frekuensi Relatif } \\
(\boldsymbol{\%})\end{array}$ & $\begin{array}{c}\text { Frekuensi } \\
\text { Kumulatif }\end{array}$ \\
\hline 1 & $2.6-3.0$ & 3 & 4.6 & 3 \\
\hline 2 & $3.2-3.6$ & 16 & 24.6 & 19 \\
\hline
\end{tabular}




\begin{tabular}{|l|c|c|c|c|}
\hline 3 & $3.7-4.1$ & 24 & 36.9 & 43 \\
\hline 4 & $4.2-4.6$ & 21 & 32,3 & 64 \\
\hline 5 & $4.7-5.1$ & 1 & 1.5 & 65 \\
\hline
\end{tabular}

Gambar 13.1 Distribusi Skor Kepuasan Kerja Guru

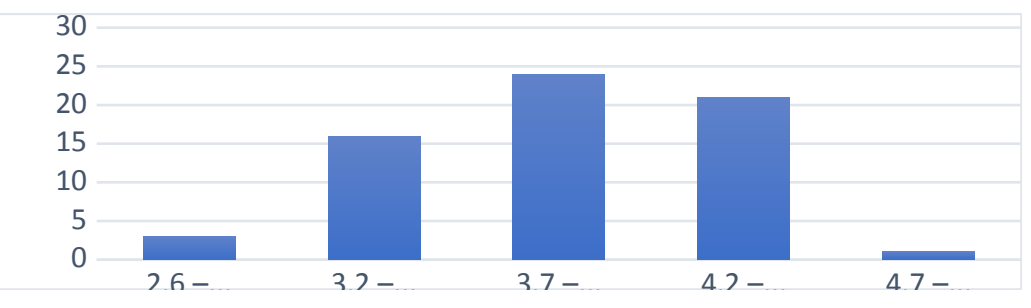

b. Budaya Organisai

Tabel. 13.3 Distribusi Frekuensi Budaya Organisasi

\begin{tabular}{|c|c|c|c|c|}
\hline No & $\begin{array}{c}\text { Interval } \\
\text { Kelas }\end{array}$ & $\begin{array}{c}\text { Frekuensi } \\
\text { Absolut }\end{array}$ & $\begin{array}{c}\text { Frekuensi } \\
\text { Relatif (\%) }\end{array}$ & $\begin{array}{c}\text { Frekuensi } \\
\text { Kumulatif }\end{array}$ \\
\hline 1 & $3.2-3.5$ & 1 & 1.5 & 1 \\
\hline 2 & $3.6-3.9$ & 5 & 7.7 & 6 \\
\hline 3 & $4.0-4.3$ & 36 & 55.4 & 42 \\
\hline 4 & $4.4-4.7$ & 14 & 21.6 & 56 \\
\hline 5 & $4.8-5.1$ & 9 & 13.8 & 65 \\
\hline \multicolumn{2}{r}{ Jumlah } & 65 & 100 & \\
\hline
\end{tabular}

Berdasarkan tabel 13.3 sebanyak $36(55,4 \%)$ responden berada pada kelompok rata-rata, $23(35,76 \%)$ di atas kelompok ratarata dan $6(9,2 \%)$ responden berada dibawah kelompok ratarata. Penyebaran (distribusi) skor budaya organisasi secara visual diperlihatkan dalam bentuk diagram batang pada gambar berikut.

Gambar 13.2 Distribusi Skor Budaya Organisasi

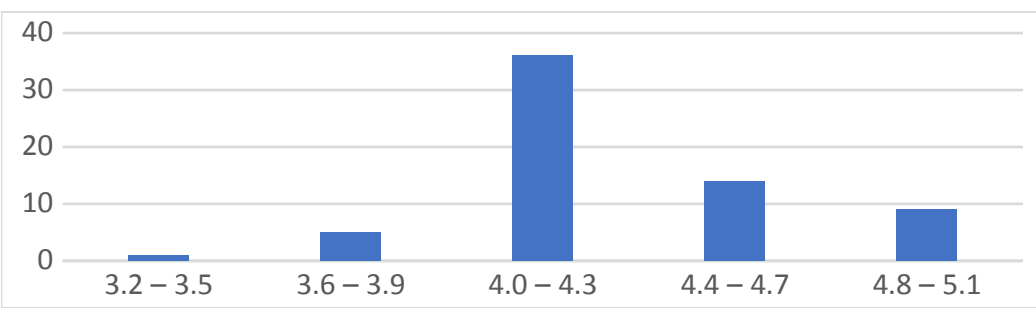

c. Kompensasi

Tabel 13.4 Distribusi Kompensasi

\begin{tabular}{|c|c|c|c|c|}
\hline No & $\begin{array}{c}\text { Interval } \\
\text { Kelas }\end{array}$ & $\begin{array}{c}\text { Frekuensi } \\
\text { Absolut }\end{array}$ & $\begin{array}{c}\text { Frekuensi } \\
\text { Relatif (\%) }\end{array}$ & $\begin{array}{c}\text { Frekuensi } \\
\text { Kumulatif }\end{array}$ \\
\hline 1 & $2.8-3.2$ & 1 & 1.5 & 1 \\
\hline 2 & $3.3-3.7$ & 8 & 12.3 & 9 \\
\hline 3 & $3.8-4.2$ & 29 & 44.6 & 38 \\
\hline 4 & $4.3-4.7$ & 22 & 33.8 & 60 \\
\hline 5 & $4.8-5.2$ & 5 & 7.7 & 65 \\
\hline \multicolumn{2}{|c|}{ Jumlah } & 65 & 100 & \\
\hline
\end{tabular}


Berdasarkan tabel 13.4 sebanyak $29(44,6 \%)$ responden berada pada kelompok rata-rata, 27 (41,5\%) di atas kelompok ratarata dan $9(13,8 \%)$ responden berada dibawah kelompok ratarata. Penyebaran (distribusi) skor kompensasi secara visual diperlihatkan dalam bentuk diagram batang pada gambar berikut.

Gambar 13.3 Distribusi Skor Kompensasi

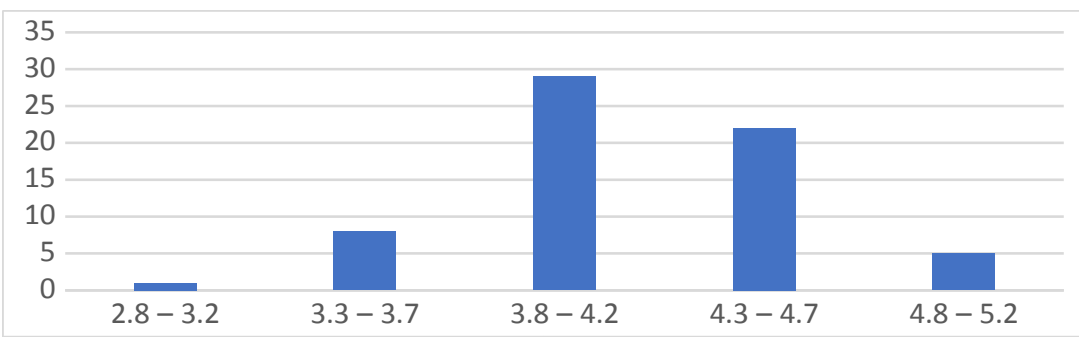

7. Uji Normalitas, Linearitas dan Homogenitas

Instrument yang sudah diuji normalitas, linearitas dan homogenitasnya, berdasarkan hasil uji normalitas diketahui nilai signifikan variabel Budaya Organisai (X1) terhadap Kepuasan Kerja Guru(Y) sebesar 0,200 dan variabel Kompensasi (X2) terhadap Kepuasan Kerja Guru (Y) sebesar 0,040. Variabel Budaya Organisai (X1) terhadap Kepuasan Kerja (Y) lebih besar dari 0,05 dan variabel Kompensasi (X2) terhadap Kepuasan Kerja (Y) lebih besar dari 0,05 sehingga hasil tersebut berdistribusi normal.

Berdasarkan uji linearitas signifikansi Deviation variabel Budaya Organisai (X1) terhadap Kepuasan Kerja Guru (Y) sebesar 0,622 dan variabel Kompensasi (X2) terhadap Kepuasan Kerja Guru (Y) sebesar 0,422. Sehingga dapat disimpulkan bahwa terdapat hubungan yang linear antara variabel Budaya Organisai (X1) terhadap Kepuasan Kerja Guru(Y) karena 0,622 lebih besar dari 0,05 dan terdapat pula hubungan linear antara variabel Kompensasi (X2) terhadap Kepuasan Kerja Guru (Y) karena 0,422 lebih besar dari 0,05.

Nilai homogenitas antara variabel Budaya Organisai (X1) dan Kompensasi (X2) terhadap Kepuasan Kerja Guru (Y) sebesar 0,875 . Sehingga dapat disimpulkan bahwa data dalam penelitian ini homogen. Karena 0,875 lebih besar dari 0,05. Pembuktian yang lainnya nilai $\mathrm{F}$ hitung sebesar 5,143 lebih besar dari F tabel yaitu 3,14.

8. Uji Hipotesis

a. Uji Hipotesis Budaya Organisasi (X1) terhadap Kepuasan Kerja Guru (Y)

Untuk mengetahui ukuran seberapa besar pengaruh Budaya Organisasi (X1) terhadap Kepuasan Kerja Guru (Y) maka dilakuakan analisis R-Square atau koefisien determinasi. 
Hasil analisis determinasi. Hasil analisis determinasi dapat dilihat pada output model summary dibawah ini.

Tabel 15.1 Koefisien Determinasi Variabel Budaya Organisasiterhadap Kepuasan Kerja

\begin{tabular}{|c|c|c|c|c|}
\hline Model & $\mathrm{R}$ & $\begin{array}{c}\mathrm{R} \\
\text { Square }\end{array}$ & $\begin{array}{c}\text { Adjusted } \\
\text { R Square }\end{array}$ & $\begin{array}{c}\text { Std. Error of the } \\
\text { Estimate }\end{array}$ \\
\hline 1 & $\begin{array}{c}0,7 \\
09\end{array}$ & 0,503 & 0,495 & 6,25916 \\
\hline
\end{tabular}

Berdasarkan perhitungan regresi linear sederhana pada tabel 15.1 didapat hasil koefisien determinasi (R Square) sebesar 0,503. Artinya pengaruh variabel bebas Budaya Organisasi terhadap variabel terikat sebesar 50,3\%. Sisanya sebesar 49,7\% disebabkan oleh faktor lain.

Selanjutnya akan dilakukan Uji t, uji t digunakan untuk menguji pengaruh $\mathrm{X} 1$ terhadap $\mathrm{Y}$. berikut adalah hasil Uji t variabel Budaya Organisasi terhadap Kepuasan Kerja Guru.

Tabel 15.2 Uji t Variabel Budaya Organisasiterhadap

Kepuasan Kerja Guru

\begin{tabular}{|c|c|c|c|c|c|}
\hline Model & \multicolumn{2}{|c|}{$\begin{array}{c}\text { Unstandardized } \\
\text { Coefficients }\end{array}$} & $\begin{array}{c}\text { Standardized } \\
\text { Coefficients }\end{array}$ & $\mathrm{t}$ & Sig. \\
\hline & $\mathrm{B}$ & $\begin{array}{c}\text { Std. } \\
\text { Error }\end{array}$ & Beta & & \\
\hline Constant & 2,356 & 9,510 & & 0,248 & 0,805 \\
\hline $\begin{array}{c}\text { Budaya } \\
\text { Organisasi }\end{array}$ & 0,587 & 0,074 & 0,709 & 7,990 & 0,000 \\
\hline
\end{tabular}

Hasil perhitungan pada tabel 15.2 didapatkan nilai konstan sebesar 2,356 dan nilai koefisien regesi variabel Budaya Organisasi sebesar 0,587. Dengan demikian persamaan regresinya yaitu:

$$
Y=2,356+0,587 X_{1}
$$

Persamaan regresi di atas memperlihatkan adanya hubungan yang berbanding lurus antara Budaya Organisasi terhadap Kepuasan Kerja Guru. Sehingga dapat diterjemahkan sebagai berikut:

- Bilai nilai X1 adalah nol maka nilai Y sama dengan 2,356

- Pengaruh X1 terhadap Y adalah 0,587 artinya bila X1 naik 1 satuan maka nilai Y naik 0,587

Hipotesis Uji t

- $\mathrm{H}_{0}$ : tidak ada pengaruh $\mathrm{X} 1$ terhadap $\mathrm{Y}$, jika nilai sig $>0,05$ dan $\mathrm{t}$ hitung $<\mathrm{t}$ tabel

- $\mathrm{H}_{1}$ : ada pengaruh $\mathrm{X} 1$ terhadap $\mathrm{Y}$, jika nilai sig $<0,05$ dan $t$ hitung $>t$ tabel

Hasil perhitungan menunjukan bahwa $\mathrm{t}$ hitung sebesar 7,990 dengan nilai signiviakan $0.000<0,05$. Maka $\mathrm{H}_{0}$ ditolak dan $\mathrm{H}_{1}$ diterima. Adapun besar pengaruhnya 0,587. 
Jadi dapat disimpulkan bahwa pengaruh Budaya Organisai (X1) terhadap Kepuasan Kerja (Y) positif.

b. Uji Hipotesis Kompensasi (X1) terhadap Kepuasan Kerja $\operatorname{Guru}(\mathrm{Y})$

Untuk mengetahui ukuran seberapa besar pengaruh Kompensasi (X2) terhadap Kepuasan Kerja Guru (Y) maka dilakukan analisis R-Square atau koefisien determinasi. Hasil analisis determinasi. Hasil analisis determinasi dapat dilihat pada output model summary dibawah ini.

Tabel 15.3 Koefisien Determinasi Variabel Kompensasi terhadap Kepuasan Kerja

\begin{tabular}{|c|c|c|c|c|}
\hline Model & $\mathrm{R}$ & $\begin{array}{c}\mathrm{R} \\
\text { Square }\end{array}$ & $\begin{array}{c}\text { Adjusted } \\
\mathrm{R} \text { Square }\end{array}$ & $\begin{array}{c}\text { Std. Error of } \\
\text { the Estimate }\end{array}$ \\
\hline 1 & 0,736 & 0,542 & 0,535 & 6,00810 \\
\hline
\end{tabular}

Berdasarkan perhitungan regresi linear sederhana pada tabel 15.3 didapat hasil koefisien determinasi (R Square) sebesar 0,542. Artinya pengaruh variabel bebas Kompensasi terhadap variabel terikat sebesar 54,2 \%. Sisanya sebesar 45,8 \% disebabkan oleh faktor lain.Selanjutnya akan dilakukan uji t, uji t digunakan untuk menguji pengaruh X2 terhadap Y. berikut adalah hasil Uji $t$ variabel Budaya Organisasi terhadap Kepuasan Kerja Guru.

Tabel 15.4 Uji t Variabel Kompensasiterhadap Kepuasan

Kerja Guru

\begin{tabular}{|l|c|c|c|c|c|}
\hline Model & \multicolumn{2}{|c|}{$\begin{array}{c}\text { Unstandardized } \\
\text { Coefficients }\end{array}$} & $\begin{array}{c}\text { Standardized } \\
\text { Coefficients }\end{array}$ & $\mathrm{t}$ & Sig. \\
\hline & $\mathrm{B}$ & $\begin{array}{c}\text { Std. } \\
\text { Error }\end{array}$ & Beta & & \\
\hline Constant & 3,591 & 8,654 & & 0,415 & 0,680 \\
\hline $\begin{array}{l}\text { Kompens } \\
\text { asi }\end{array}$ & 0,598 & 0,069 & 0,736 & 8,641 & 0,000 \\
\hline
\end{tabular}

Hasil perhitungan pada tabel 15.4 didapatkan nilai konstan sebesar 3,591 dan nilai koefisien regesi variabel Kompensasi sebesar 0,598. Dengan demikian persamaan regresinya yaitu:

$$
Y=3,591+0,598 X_{2}
$$

Persamaan regresi di atas memperlihatkan adanya hubungan yang berbanding lurus antara Kompensasi terhadap Kepuasan Kerja Guru. Sehingga dapat diterjemahkan sebagai berikut:

- Bilai nilai X2 adalah nol maka nilai Y sama dengan 3,591

- Pengaruh X2 terhadap Y adalah 0,598 artinya bila X2 naik 1 satuan maka nilai Y naik 0,598

Hipotesis Uji t 
- $\mathrm{H}_{0}$ : tidak ada pengaruh $\mathrm{X} 2$ terhadap $\mathrm{Y}$, jika nilai sig $>0,05$ dan $t$ hitung $<\mathrm{t}$ tabel

- $\mathrm{H}_{1}$ : ada pengaruh $\mathrm{X} 2$ terhadap $\mathrm{Y}$, jika nilai sig $<0,05$ dan $t$ hitung $>t$ tabel

Hasil perhitungan menunjukan bahwa $\mathrm{t}$ hitung sebesar 8,641 dengan nilai signifikan $0.000<0,05$. Maka $\mathrm{H}_{0}$ ditolak dan $\mathrm{H}_{1}$ diterima. Adapun besar pengaruhnya 0,598. Jadi dapat disimpulkan bahwa pengaruh Kompensasi (X2) terhadap Kepuasan Kerja (Y) positif.

c. Uji Hipotesis Budaya Organisasi (X1) dan Kompensasi (X2) terhadap Kepuasan Kerja Guru (Y)

Korelasi adalah ukuran hubungan linear antara dua variabel. Dalam perhitungan korelasi akan didapat koefisien korelasi. Koefisien korelasi ini digunakan untuk mengetahui keeratan hubungan, arah hubungan dan hubungan tersebut signifikan atau tidak. Erat dan tidaknya hubungan antar dua variabel dapat ditentukan dengan tabel berikut ini.

Tabel 15.5 Pedoman Derajat Hubungan

\begin{tabular}{|c|c|}
\hline Rentang Nilai & Korelasi \\
\hline $0,00 \mathrm{~s} / \mathrm{d} 0,20$ & Tidak Ada Korelasi \\
\hline $0,20 \mathrm{~s} / \mathrm{d} 0,40$ & Korelasi Lemah \\
\hline $0,40 \mathrm{~s} / \mathrm{d} 0,60$ & Korelasi Sedang \\
\hline $0,60 \mathrm{~s} / \mathrm{d} 0,80$ & Korelasi Kuat \\
\hline $0,80 \mathrm{~s} / \mathrm{d} 1,00$ & Korelasi Sempurna \\
\hline
\end{tabular}

Tabel 15.6 Matrik Korelasi Antar Variabel

\begin{tabular}{|c|c|c|c|c|c|c|c|c|c|}
\hline \multirow{2}{*}{ Model } & \multirow[t]{2}{*}{$\mathrm{R}$} & \multirow[t]{2}{*}{ R Square } & \multirow{2}{*}{$\begin{array}{l}\text { Adjusted R } \\
\text { Square }\end{array}$} & \multirow{2}{*}{$\begin{array}{l}\text { Std. Error } \\
\text { of the } \\
\text { Estimate }\end{array}$} & \multicolumn{5}{|c|}{ Change Statistics } \\
\hline & & & & & $\begin{array}{l}\mathrm{R} \text { Square } \\
\text { Change }\end{array}$ & F Change & df1 & $\mathrm{d} f 2$ & $\begin{array}{l}\text { Sig. F } \\
\text { Change }\end{array}$ \\
\hline 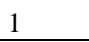 & $.776^{\mathrm{a}}$ & 0,602 & 0,590 & 5,64555 & 0,602 & 46,959 & 2 & 62 & 0,000 \\
\hline
\end{tabular}

Berdasarkan tabel 15.6 nilai signifikasi $\mathrm{F}$ hitung 0,00 lebih kecil dari 0,05 sehingga dapat disimpulkan bahwa terdapat hubungan antara variabel Budaya Organisai (X1) dan Kompensasi (X2) terhadap Kepuasan Kerja (Y).

Dari hasil tabel 4.10 didapat $\mathrm{R}$ hitung sebesar 0,776. Jika dilihat dari pedoman derajat hubungan pada tabel 4.9 nilai $\mathrm{R}$ hitung diantara 0,60 sampai dengan 0,80 sehingga dapat disimpulkan bahwa variabel Budaya Organisai (X1) dan Kompensasi (X2) terhadap Kepuasan Kerja (Y) memiliki korelasi yang kuat.

Tabel 15.7 Uji F Budaya Organisasi dan Kompensasi terhadap Kepuasan Kerja

\begin{tabular}{|c|c|c|c|c|c|c|}
\hline \multicolumn{2}{|c|}{ Model } & $\begin{array}{c}\text { Sum of } \\
\text { Squares }\end{array}$ & df & $\begin{array}{c}\text { Mean } \\
\text { Square }\end{array}$ & F & Sig. \\
\hline \multirow{2}{*}{1} & Regression & 2993,370 & 2 & 1496,685 & 46,959 & $.000^{\mathrm{b}}$ \\
\cline { 2 - 7 } & Residual & 1976,076 & 62 & 31,872 & & \\
\cline { 2 - 7 } & Total & 4969,446 & 64 & & & \\
\hline
\end{tabular}

Berdasarkan tabel 4.11 di dapat nilai $\mathrm{F}$ sebesar 46,959 dengan signivikansi $0,00<0,05$. Artinya Budaya Organisasi 
(X1) dan Kompensasi (X2) secara simultan berpengaruh terhadap Kepuasan Kerja Guru (Y).Dapat dibuktikan dengan menguji nilai $\mathrm{F}$ hitung.Jika $\mathrm{F}$ hitung $>\mathrm{F}$ tabel maka Budaya Organisasi (X1) dan Kompensasi (X2) secara simultan berpengaruh terhadap Kepuasan Kerja Guru (Y). $F$ hitung di dapat 46,959 > F tabel yaitu 3,14. Sehingga dapat disimpulkan bahwa Budaya Organisasi (X1) dan Kompensasi (X2) secara simultan berpengaruh terhadap Kepuasan Kerja Guru (Y).

\section{Budaya Organisasi terhadap Kepuasan Kerja Guru}

Hasil analisis penelitian ini menunjukan bahwa Budaya Organisasi terhadap Kepuasan Kerja Guru memiliki pengaruh positif. Dimana ini menunjukan bahwa semakin baik Budaya Organisasi di SD, SMP Pembangunan Jaya maka semakin tinggi pula kepuasan Kerja yang dirasakan guru SD, SMP Pembangunan Jaya. Hal tersebut sama dengan penelitian sebelumnya yaitu penelitian Putra, dkk (2014) yang menyatakan Budaya Organsisasi berpengaruh positif terhadap Kepuasan Kerja.

Budaya Organisasi yang baik akan berdampak pada lingkungan kerja yang baik. Dimana anggota organisasi akan merasa puas jika budaya organisasinya baik. Budaya Organisasi dalam penelitian adalah sekolah, maka sekolah yang baik akan berdampak pada kepuasan kerja guru dalam mengajar. Jadi semakin tinggi Budaya Organisasi, maka semakin tinggi pula Kepuasan Kerja yang dirasakan oleh guru.

\section{Kompensasi terhadap Kepuasan Kerja Guru}

Hasil analisis penelitian ini menunjukan bahwa Kompensasi terhadap Kepuasan Kerja Guru memiliki pengaruh positif. Dimana ini menunjukan bahwa semakin tinggi Kompensasi di SD, SMP Pembangunan Jaya maka semakin tinggi pula Kepuasan Kerja yang dirasakan guru SD, SMP Pembangunan Jaya. Hal tersebut sama dengan penelitian sebelumnya yaitu penelitian Permadi \& Wayan (2017) yang menyatakan Kompensasi berpengaruh positif terhadap Kepuasan Kerja.

Kompensasi merupakan hal terpenting bagi seorang pegawai, karena tidak hanya mencangkup upah atau gaji.Dalam penelitian ini kompensasi yang diterima setiap guru sesuai dengan beban kerjanya.Sehingga para guru SD, SMP Pembangunan Jaya sudah merasa puas dalam bekerja. Namun kompensasi yang baik akan memberikan kepuasan kerja yang baik. Semakin tinggi kompensasi maka semakin tinggi pula kepuasan kerja yang diarasakan oleh guru.

\section{Budaya Organisasi dan Kompensasi terhadap Kepuasan Kerja Guru}

Hasil analisis penelitian ini menunjukan bahwa Budaya Organisasi dan Kompensasi terhadap Kepuasan Kerja Guru memiliki pengaruh positif. Dimana ini menunjukan bahwa semakin tinggi Budaya Organisasi dan Kompensasi di SD, SMP Pembangunan Jaya maka semakin tinggi pula Kepuasan Kerja yang dirasakan guru SD, SMP Pembangunan Jaya. Hal 
tersebut sama dengan penelitian sebelumnya yaitu Nurdin (2010) yang menyatakan Kompensasi berpengaruh positif terhadap Kepuasan Kerja. Budaya Organisasi dan Kompensasi sangat mempengarushi Kepuasan Kerja, karena Budaya Organisasi merupakan salah satu faktor yang dapat memengaruhi Kepuasan Kerja seseorang. Selain itu Kompensasi juga memengaruhi Kepuasan Kerja, karena pemberian Kompensasi yang baik akan menciptakan rasa Kepuasan tersendiri bagi seorang pegawai. Budaya sekolah yang baik serta Kompensasi yang baik dapat memengaruhi Kepuasan Kerja Guru.

\section{KESIMPULAN, IMPLIKASI DAN SARAN}

\section{Kesimpulan}

Dari hasil penelitian yang dilakukan di SD, SMP Pembanguan Jaya berdasarkan hasil perhitungan dan analisis data dapat ditarik kesimpulan sebagai berikut:

a. Budaya organisasi memengaruhi Kepuasan Kerja Guru SD, SMP Pembangunan Jaya sebesar 50,3\% sisanya 49,7\% adalah faktor lain. Hasil $t$ hitung dengan siginivikansi $0,000<0,05$ artinya ada pengaruh Budaya Organisasi terhadap Kepuasan Kerja Guru sebesar 0,587.

b. Kompensasi memengaruhi Kepuasan Kerja Guru SD, SMP Pembangunan Jaya sebesar 54,2 \% sisanya 45,8\% adalah faktor lain. Hasil thitung dengan siginivikansi $0,000<0,05$ artinya ada pengaruh Kompensasi terhadap Kepuasan Kerja Guru sebesar 0,598.

c. Budaya Organisasi dan Kompensasi secara Bersama-sama memengaruhi Kepuasan Kerja Guru sebesar $59 \%$ sisanya $41 \%$ adalah faktor lain. Hasil $\mathrm{F}$ hitung dengan siginivikansi $0,000<0,05$ artinya ada pengaruh Budaya Organisasi dan Kompensasi terhadap Kepuasan Kerja Guru dengan korelasi kuat sebesar 0,776.

\section{Saran}

Berdasarkan penelitian ternyata terdapat variabel lain yang yang nilainya cukup besar dalam memengaruhi guru dalam kepuasan kerja. Bagi peneliti yang akan datang perlu menambahkan variabel lain selain budaya organisasi dan kompensasi. Misalnya kepemimpinan, motivasi dan jenjang karir.

\section{DAFTAR PUSTAKA}

Handoko, T. Hani. 2014. Manajemen Personalia dan Sumberdaya Manusia. Yogyakarta: BPFE

Hasibuan, Malayu S.P. 2018. Manajemen Sumber Daya Manusia. Jakarta: Bumi Aksara.

Mangkunegara, A.A Anwar Prabu. 2017. Manajemen Sumber Daya Manusia Perusahaan. Bandung: Remaja Rosdakarya.

Robbins S.P. and Judge T.A., 2011. Organizational Behavior Fourteenth Edition, New Jersey: Prentince Hall

Sedarmayanti. 2016. Manajemen Sumber Daya Manusia. Bandung: Refika Aditama. 
Simamora, Henry. 2006. Manajemen Sumber Daya Manusia. Edisi Kedua. Yogyakarta: BP STIE YKPN.

Sugiyono. 2018. Metode Penelitian Kuantitatif, Kualitatif, dan R\&D. Bandung: Alfabeta

Sukardi, 2008. Metodologi Penelitian Pendidikan: Kompetensi dan Praktiknya. Jakarta: Bumi Aksara

Tampubolon, P. Manahan. 2015. Perilaku Keorganisasian (Organization Behavior). Bogor: Ghalia Indonesia.

Winardi, J. 2015. Manajemen Perilaku Organisasi. Jakarta: Prenadamedia Group. 